\title{
A Large Celiac Artery Aneurysm
}

\author{
Harinder Singh Bedi*, Kamal Negi \\ Department of Cardiovascular, Thoracic Surgery Christian Medical College \& Hospital, Ludhiana, India \\ Email: *drhsbedicmc@gmail.com, *drhsbedi12@yahoo.com
}

Received May 11, 2013; revised June 12, 2013; accepted June 20, 2013

Copyright (C 2013 Harinder Singh Bedi, Kamal Negi. This is an open access article distributed under the Creative Commons Attribution License, which permits unrestricted use, distribution, and reproduction in any medium, provided the original work is properly cited.

\section{ABSTRACT}

We report preoperative, intraoperative and postoperative images of a large celiac artery aneurysm.

Keywords: Celiac Artery Aneurysm; Graft

A 40-year-old lady presented with complaints of an upper abdominal swelling of recent onset. A multislice CT angiogram (Figure 1) revealed a giant aneurysm of the celiac artery. The aneurysm was $15 \times 12.7 \mathrm{~cm}$-the largest reported in the literature [1]. The patient underwent successful resection of the aneurysm (Figure 2) and revascularization with a ringed synthetic graft from the aorta to the hepatic artery (Figure 3) - the hepatic artery did not have any significant backflow. The splenic artery

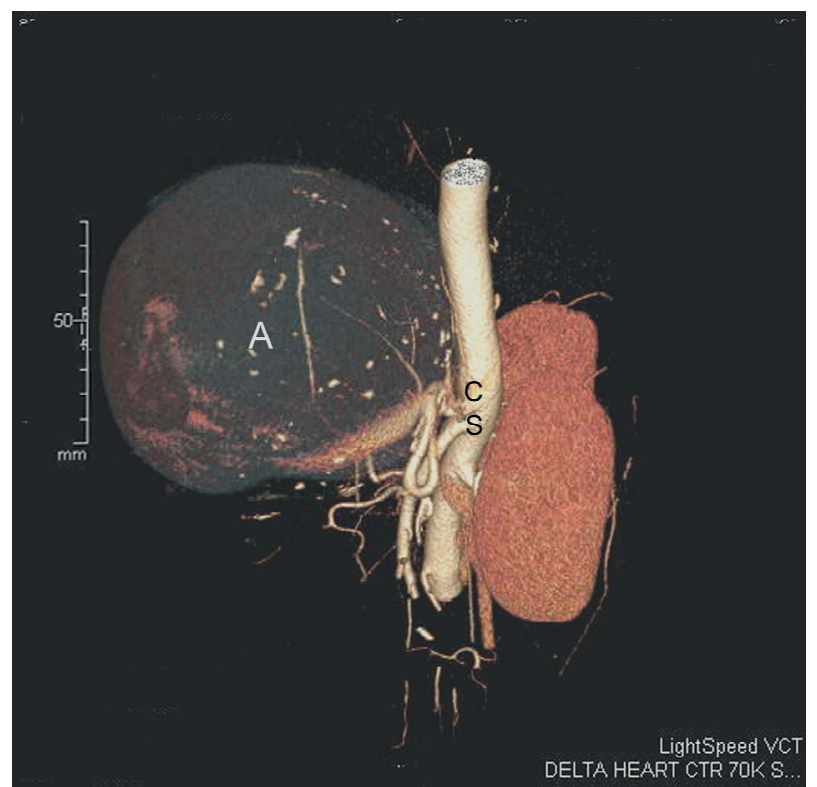

Figure 1. (cover image): CT angiogram showing the large aneurysm (A) arising from the celiac artery (C), S = superior mesenteric artery.

${ }^{*}$ Corresponding author.

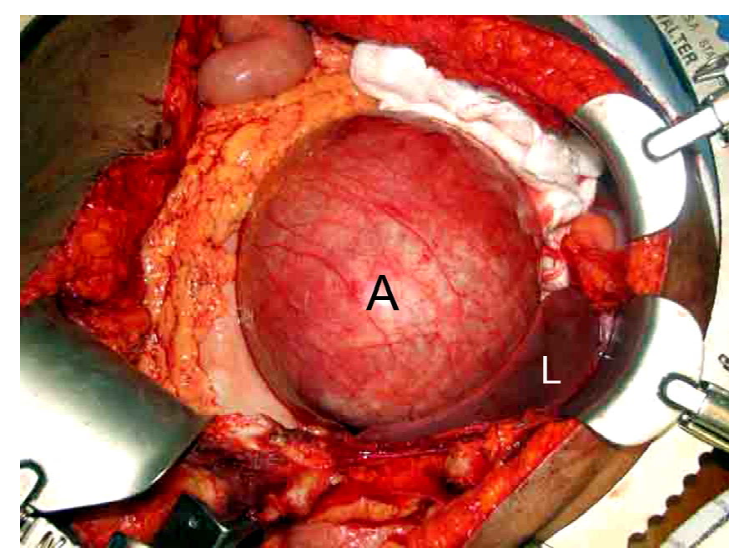

Figure 2. Intraoperative photograph showing the large aneurysm at laparotomy. $\mathrm{A}$ = aneurysm; $\mathrm{L}=$ liver.

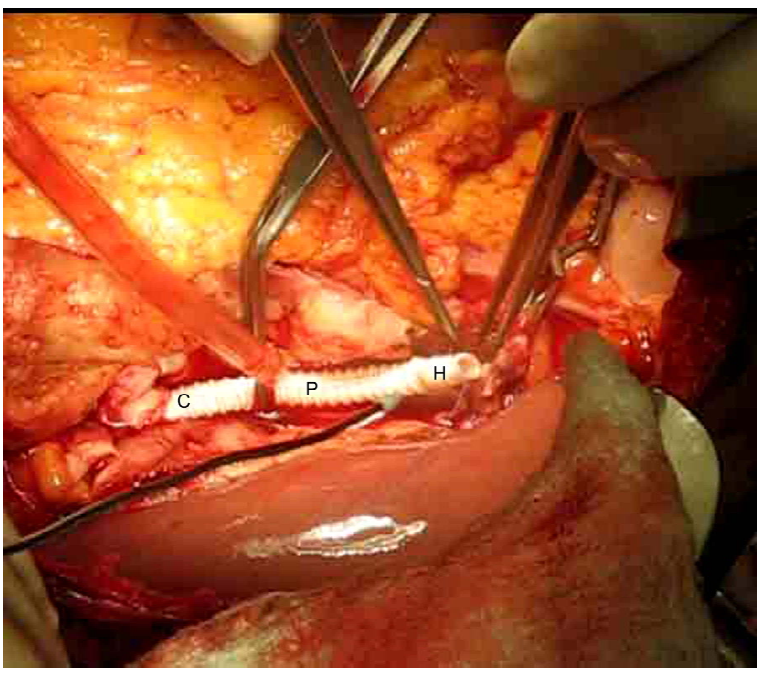

Figure 3. Ringed graft between the celiac and hepatic artery. $\mathrm{C}=$ celiac artery end; $\mathbf{P}$ = graft; $\mathbf{H}=$ hepatic artery end. 


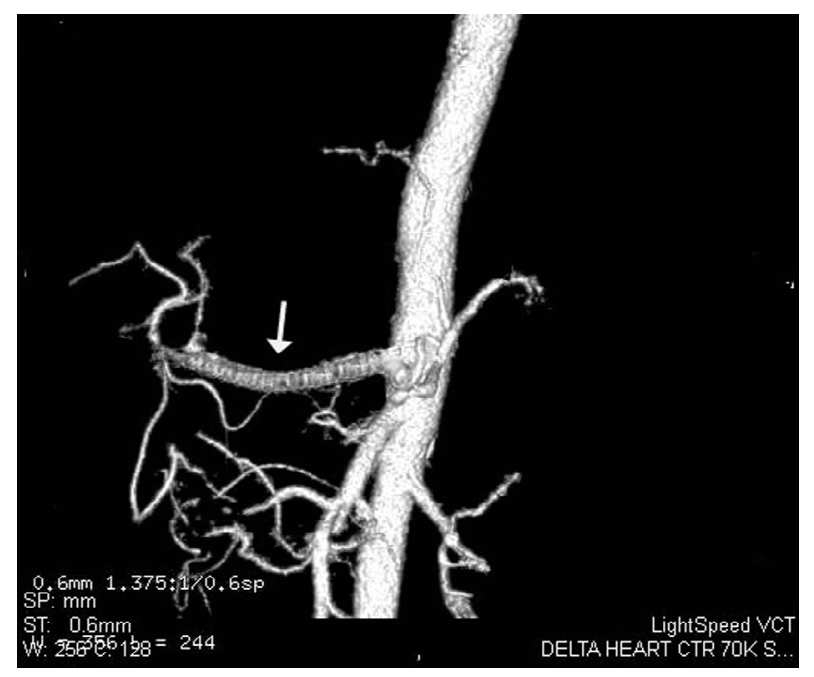

Figure 4. Post op CT angiogram showing good patency of the graft (arrow). was friable and had a very good backflow and so was ligated. The left gastric artery could not be separately identified. Histopatholgy showed all layers (true aneurysm) but did not reveal any specific etiology. A post op CT angiogram showed a good flow in the graft (Figure 4).

\section{REFERENCES}

[1] D. M. McMullan, M. McBride, J. L. Livesay, K. G. Dougherty and Z. Krajcer, "Celiac Artery Aneurysm-A Case Report,” Texas Heart Institute Journal, Vol. 33, No. 2, 2006, pp. 235-240. 